\title{
A DIGITAL IMAGE METHOD FOR ANALYSIS OF SOIL PORES
}

\author{
Shufang Jiang ${ }^{1,2}$, Yaohu Kang ${ }^{1, *}$, Zeqiang Sun ${ }^{1}$ \\ ${ }^{1}$ Institute of Geographic Sciences and National Resources Research, Chinese Academy \\ of Science, Beijing P. R. China 100101 \\ ${ }^{2}$ Graduate University of Chinese Academy of Science, Beijing P. R. China 100039 \\ * Corresponding author, Address: Institute of Geographic Sciences and National Resources \\ Research, Chinese Academy of Science, Beijing P. R. China 100101 Tel: +86-10-64856516, \\ Fax:+86-10-64856516, Email: kangyh@igsnrr.ac.cn
}

Abstract: Measurements of porosity and pore size distribution provide important data on the physical properties of soils. This paper presents a digital image method for the analysis of soil pores. In the analysis of soil thin sections, the image threshold separating pore space from the surrounding solid, as well as the capillary pore size threshold separating air pores and capillary pores, was obtained by analysis of the thin sections of calibration samples where values of total porosity and capillary porosity were pre-determined by traditional soil physics methods (IM). The total porosity and capillary porosity, as well as percentages of pores of a particular size, of all samples of similar soil type can then be determined by these image thresholds in thin section image analysis. The maximum capillary pore size in soils can also be determined. Because the thresholds for the total porosity and capillary porosity are determined based on physical soil characteristics in this method, the error associated with existing methods (caused by subjective threshold estimates) was overcome. Small variations in results proved that this method has good accuracy and is acceptable. Any personal computer and flatbed scanner, along with any commercial remote sensing software (ENVI, PCI, ERDAS, etc.) and Geographic Information System software (ArcGIS, ArcView, SuperMap, etc.) are sufficient to complete the method. In addition, the method can also be used for analysis of pore shapes and arrangements.

Keywords: digital image method, image threshold, soil pore distribution, soil porosity

Please use the following format when citing this chapter:

Jiang, S., Kang, Y. and Sun, Z., 2009, in IFIP International Federation for Information Processing, Volume 294, Computer and Computing Technologies in Agriculture II, Volume 2, eds. D. Li, Z. Chunjiang, (Boston: Springer), pp. 1029-1038. 


\section{INTRODUCTION}

Measurements of porosity and pore size distribution provide important data on soil physical properties. Porosity (n) of a given volume of soil is defined as the ratio of pore volume to the total soil volume. In a traditional density measurement method (DMM), porosity is measured indirectly from the bulk density $\left(\rho_{b}\right)$ and particle density $\left(\rho_{p}\right)$ by the equation $\mathrm{n}=100[1-$ $\left(\rho_{b} / \rho_{p}\right)$ ] (Hillel, 1980). The result obtained using DMM is the total porosity. It is, however, difficult to measure the percentage of pores with different sizes, such as capillary pores and air pores.

The intrusion method (IM) is another method and is the most popular method used in practice. In IM, total porosity is determined by the volume of liquid that just fills the open spaces and completely saturates a soil sample, divided by sample volume (Lawrence, 1977; Hillel, 1980). The porosity of capillary pores is determined by the field water capacity (the volumetric water content of the soil sample, determined once the saturated soil sample has been left to drain completely, under gravity, for over 8 hours) divided by the sample volume. Air porosity is calculated by the total porosity minus the capillary porosity.

With the rapid development of computational techniques, image analysis has been used to analyze the images of resin-impregnated thin sections (thin sectioning method, TSM) for determining both the total porosities and pore sizes of soils. The procedure of TSM includes: (1) obtaining the images of the resin-impregnated thin sections using optical or electron microscope (Bouma et al., 1977; Chen et al., 1980; Pagliai et al., 1983), X-ray scanning (Brandsma et al., 1999) or combinations of more than one of these techniques (Cousin et al., 2005); and (2) analysis of the images using commercial or specialized computer software to segment soil grains and pores.

The accuracy of TSM mainly depends on the image analysis. One method for image analysis is implemented by counting pixels with the same features according to a predetermined grey scale level using computer software (Murphy et al, 1977). To overcome low resolution image pixels allocated as both solid and void, Vogel and Kretzschmar (1996) implemented a program to segment the images into solid and void using the bi-level-segmentation based on the original grey scale level histogram of the images. Li et al. (2004) photographed thin sections under high intensity ultraviolet light. The photographs are scanned and image threshold operate using the maximum color intensity. The experimental errors are obtained by duplicate estimates from numerous images. Another method for image analysis has been recently developed using multi-spectral image technology. Multi-spectral images are collected from soil thin sections, always using transmitted, reflected or polarized illumination (Protz and VandenBygaart, 1998). Then 
supervised and unsupervised classification techniques in RS (Remote Sensing) software are used to separate voids and other features into several classes, which are then aggregated to individual features by reference to conventional micromorphology or point counting methods. For the purpose of improving multi-spectral image analysis, Adderley et al. (2002) provided a linkage, obtained by empirical observation, to traditional micromorphological description procedures.

The main principle for the pore size classification is the equivalent pore diameter (diameter of a circle having an area equal to the pore area). Different investigators have subdivided the continuous pore-size distribution of a soil into classes with different criteria based on their primary functions (White, 2006). Pagliai et al. (1983) investigated the pore size distribution of the clay loam soil using 9 classes. Pores with diameter $>1.0 \mathrm{~mm}$ in equivalent diameter were considered to be macropores (Singh et al., 1991; Li et al., 2002). Velde et al. (1996) classified pores with less than a given width of $2.5 \mathrm{~mm}$ as being small. Fox et al. (2004) subdivided the pores into four size classes $(50 \sim 200,200 \sim<350,350 \sim<500$, and $\geqslant 500 \mu \mathrm{m})$. These pore size classification methods were implemented using sizes determined by empirical or given values.

This paper presents a method for analyzing soil pores by obtaining digital images of resin-impregnated thin sections of soils using a personal flatbed scanner. Image thresholds for separating the pore space and solid, and for separating capillary pores and air pores, were determined with commercial RS and GIS software on a personal computer using values of total porosity and capillary porosity of calibration samples measured by traditional soil physics methods. The total porosity and capillary porosity, as well as percentages of pores of a particular size, of all samples of similar soil type can then be determined by image thresholds. In addition, the pores can be divided into air pores and capillary pores using the capillary pore threshold. The maximum capillary pore size in this soil type can also be determined by the capillary pore threshold.

\section{METHODOLOGY AND PROCEDURES}

\subsection{Methodology}

Solid and pore spaces impregnated with resin blended with dye display different colors on a thin section made using the TSM. It was found that the color is deeper near the center of the void space while it is lighter near the center of the solid section, and changes gradually in the boundary region from void space to solid in digital images of the thin section taken using a 
personal flatbed scanner. A pore space may comprise several pixels. For the same pore space, pixel number depends on the scanner resolution, increasing as scanner resolution increases. According to the computer technology for image analysis in RS, each pixel has a digital number (DN), where deeper colors have a smaller DN and lighter colors have a larger DN. In this classification, pixels belonging to pore spaces have smaller DN values and those belonging to the solid have larger $\mathrm{DN}$ values in the thin section digital image. If the pixel number for each $\mathrm{DN}$ is determined, the percentage pixel number corresponding to each DN relative to the total pixel number of the digital image can be calculated. Next, the cumulative total percentage of the range from the smallest $\mathrm{DN}$ to any $\mathrm{DN}$ is calculated. If calculated starting from the smallest DN and continuing for increasing DN until the cumulative percentage is approximately equal to the value of soil porosity predetermined by IM, the DN at this point can be taken as the threshold DN for the image, because the summation at this point is also equal to the total number of void pixels divided by the total number of pixels in the image, i.e. soil porosity. And this image threshold allows the image to be divided into two parts: pore and solid. The resulting binary image contains information specifying only whether the pixel is solid or pore.

In the binary image, each individual pixel, and each patch composed of several connected pixels, is the pores. The larger the number of pixels, the larger the pore, and the smallest possible pore size is 1 pixel. The pore size can be calculated by:

$$
D=2 \sqrt{\frac{n A}{N \pi}}
$$

where

$\mathrm{D}=$ equivalent diameter of a pore $(\mathrm{mm})$

$n=$ number of pixels in the pore

$\mathrm{N}=$ total number of pixels in the digital image

$\mathrm{A}=$ area of the digital image $\left(\mathrm{mm}^{2}\right)$

$\pi=3.1416$

The diameter of every pore can be calculated using Eq. (1). The percentage area $(\mathrm{P})$ of any size pore in the digital image can be calculated by:

$$
P=\frac{C_{n} \times n}{N}
$$

Where $\mathrm{C}_{n}=$ number of pores with $\mathrm{n}$ pixels.

The capillary porosity can therefore be calculated by the total area of capillary pores divided by the total area of the thin section in the digital image. In thin section image analysis, the cumulative total of the percentage area of pore patches, starting with the smallest patch and adding contributions from increasing patch sizes, is calculated until the summation approximately equals the capillary porosity pre-measured using IM. The 
cumulative percentage at this point is the total capillary pore area divided by the total area of the thin section, i.e. capillary porosity. At this point, the largest $\mathrm{D}$ reached corresponds to the largest capillary pore and the corresponding pixel number (n) is the threshold for capillary pores.

Using image threshold and capillary threshold, for total porosity and capillary pore size, the total porosity, capillary porosity, capillary pore size and percentage of different size pores of similar soil can be analyzed.

\subsection{Procedures}

According to the methodology described above, a procedure for soil pore analysis is developed as follows:

(1) Take a representative soil sample and pass it through a sieve after airdrying. Place the soil into three PVC plastic cylinders (three repetitions) with diameters of $\geqslant 63 \mathrm{~mm}$, heights $\geqslant 50 \mathrm{~mm}$ and a filter paper at the bottom. These will be used as calibration samples.

(2) Measure soil porosity and capillary porosity of the calibration samples using IM and retain them for further analysis.

(3) Collect undisturbed soil samples and store in similar PVC cylinders to those used in Step (1). These are now the samples to be used for investigation. Avoid soil samples containing many roots or stones.

(4) Oven-dry all samples including the calibration samples from Step (2). Impregnate all samples with Epoxy resin mixed with dye, under vacuum conditions, using TSM. After the samples have solidified, make thin sections for each sample again following the TSM.

(5) Scan the thin sections of the calibration samples with a personal flatbed scanner. Considering scanning time, storage space and quality of the images, a scan resolution of $2400 \mathrm{dpi}$ is recommended. Record the real scan area (A) of each thin section. Be sure to choose the same scan mode in this step, especially the color mode and zooming size. Save the images as tiff files.

(6) Input the images of the thin sections of the calibration samples into RS software. Using the statistical function in the RS software, calculate the percentage pixel numbers corresponding to each $\mathrm{DN}$, relative to the total pixel number of the digital image, and calculate the cumulative percentage starting with the smallest DN and increasing. Output these results in the statistics parameter table.

(7) Find out the summation of the percentage value approximates to the corresponding samples' soil porosity measured in step (2) from the statistics parameter tables. Determine which cumulative percentage from Step (6) best approximates the corresponding samples' soil porosity from Step (2). Record their respective DN values. 
(8) Considering sample variance and differences between individual samples, calculate the mean DN value from all the thin sections of the calibration samples. This number is the image threshold for total soil porosity.

(9) Convert original digital images of calibration samples to binary images according to the image threshold, using the classify function in the RS software.

(10) Input the binary images of calibration samples into GIS software, using the reclassify function to identify the patches. Pore patches are assigned value of 1 and colored black. Solid patches are assigned values of NoData and colored white.

(11) Use the region-group function to calculate the pixel number of each pore patch $(n)$, the number of patches with $n$ pixels $\left(C_{n}\right)$, and the total pixel number of images $(\mathrm{N})$ of the binary images of calibration samples. Transfer these results from an attribute table to an Excel file.

(12) Sorting the output Excel file by the field of connection pixel number, calculate the cumulative percentage area of the patches $\left(\mathrm{P}_{c}\right)$ in each digital image, starting with the smallest area and continuing for increasing areas until the cumulative percentage approximates the capillary porosity measured using IM. Record the corresponding connection pixels number in each image respectively. Calculate the mean value of these numbers $\left(\mathrm{n}_{\mathrm{c}}\right)$.

(13) Considering sample variance and differences between individual samples, define $\mathrm{n}_{\mathrm{c}}$ as the capillary pore threshold of this batch of samples.

(14) Substitute $n$ in Eq. (1) with $n_{c}$, so that the maximum capillary pore size $\left(D_{C}\right)$ of this batch of samples can be calculated.

(15) Input the thin section images of the samples to be investigated into RS software. Using the statistical function in the RS software, output the statistics parameter tables. Next, determine the total porosity $\left(\mathrm{P}_{\mathrm{t}}\right)$ of the thin section of each investigation sample by using the spreadsheet column showing the cumulative percentage $\mathrm{DN}$, along with the image porosity threshold from the corresponding output table.

(16) Convert original digital images of all investigation samples to binary images, using the image porosity threshold and the classify function in the RS software.

(17) Input the binary images of all the investigation samples into GIS software, record the patch areas as for step (10), and apply the region-group function to output the attribute table to an excel file as described in Step (11). Divide the pores into capillary pores and air pores according to the capillary pore threshold.

(18) Calculate the porosity of capillary pores of each investigation sample using Eq. (2).

(19) Calculate the porosity of the air pores of each investigation sample using the subtraction Pt-P. 
(20) Calculate the diameter of any pore from the Excel file of each investigation sample by using Eq. (1).

(21) Calculate the porosity of any size pore from the Excel file of each investigating sample by using Eq. (2).

The binary images can also be used for further analysis of pores, such as pore shape, according to the investigation requirements.

\section{VERIFICATION}

Three types of soils were selected and analyzed to verify the method presented in this paper. Soil samples with different bulk densities, and consisting of sandy soil, latosolic red soil and fluvo-aquic soil, were prepared using the method in Step (1) with sample numbers of 20,30 and 28, respectively. For the sandy soil, 2 calibration samples were selected randomly from the samples with bulk density of $1.7 \mathrm{~g} / \mathrm{cm}^{3}$ and 1 calibration sample was selected randomly from samples with bulk density of $1.8 \mathrm{~g} / \mathrm{cm}^{3}$. For the latosolic red soil, each calibration sample was selected randomly from the samples with bulk densities of $1.1,1.3$ and $1.4 \mathrm{~g} / \mathrm{cm}^{3}$. For fluvoaquic soil, each calibration sample was selected randomly from the samples with bulk densities of $1.2,1.4$ and $1.6 \mathrm{~g} / \mathrm{cm}^{3}$. Relevant soil information is summarized in Table1.

Table 1 Parameters of soil samples

\begin{tabular}{lccccccccccccc}
\hline & \multicolumn{3}{c}{ Sandy soil } & \multicolumn{3}{c}{ Latosolic red soil } & \multicolumn{3}{c}{ Fluvo-aquic soil } \\
\hline Sites & \multicolumn{3}{c}{ North China Plain } & \multicolumn{3}{c}{ South of China } & \multicolumn{5}{c}{ North China Plain } \\
Total number & \multicolumn{4}{c}{20} & \multicolumn{4}{c}{30} & \multicolumn{7}{c}{28} \\
Density $\left(\mathrm{g} / \mathrm{m}^{3}\right)$ & 1.7 & 1.8 & 1.1 & 1.2 & 1.3 & 1.35 & 1.4 & 1.2 & 1.3 & 1.4 & 1.5 & 1.6 \\
calibration samples & 2 & 1 & 1 & 0 & 1 & 0 & 1 & 1 & 0 & 1 & 0 & 1 \\
sample repetitions & 8 & 9 & 5 & 6 & 5 & 6 & 5 & 5 & 6 & 5 & 5 & 4 \\
\hline
\end{tabular}

Figs. 1(a), (b) and (c) show the binary images for one calibration sample of sandy soil, one calibration sample of latosolic red soil and one calibration sample of fluvo-aquic soil, respectively. Total porosity data for each soil, measured using IM and the method presented in this paper, are listed in Table 2.

Analysis found that relative errors associated with the three soil sample types are all $<12 \%$. In sandy soil samples, almost all the relative errors are $<$ $5 \%$. For fluvo-aquic soil, $75 \%$ of samples have relative errors $<5.5 \%$. For latosolic red soil, nearly $90 \%$ of the samples have relative errors $<5 \%$. The mean relative error for all the soils is $<5.5 \%$ (Table 2). Statistical analysis (the paired samples T Test) shows there is no significant difference between the two methods for the three types of soils with different densities at $\mathrm{P}<$ 0.01 . 


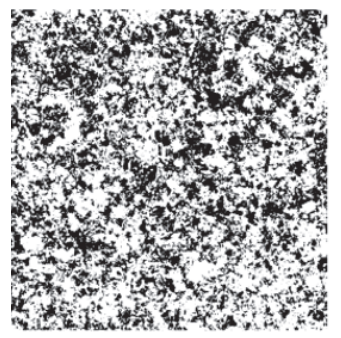

(a)

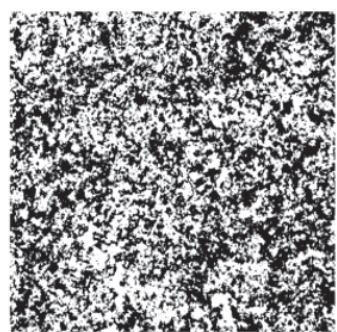

(b)

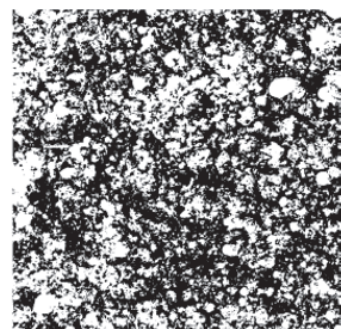

(c)

Fig. 1 Soil binary images (pore is black and solid is white) covering $1 \mathrm{~cm} \times 1 \mathrm{~cm}$. (a) Sandy soil; (b) Fluvo-aquic soil; (c) Latosolic red soil.

Table 2 Soil porosity (\%) data using IM and the presented method

\begin{tabular}{lcccccccccccc}
\hline & \multicolumn{4}{c}{ Sandy soil } & \multicolumn{4}{c}{ Latosolic red soil } & \multicolumn{4}{c}{ Fluvo-aquic soil } \\
\hline Density $\left(\mathrm{g} / \mathrm{m}^{3}\right)$ & 1.7 & 1.8 & 1.1 & 1.2 & 1.3 & 1.35 & 1.4 & 1.2 & 1.3 & 1.4 & 1.5 & 1.6 \\
Mean_1 & 32.69 & 32.65 & 58.80 & 59.94 & 61.03 & 59.80 & 59.97 & 48.57 & 51.68 & 54.57 & 57.04 & 55.81 \\
SD_1 & 1.39 & 1.58 & 1.68 & 1.23 & 1.09 & 1.68 & 1.74 & 1.71 & 2.59 & 3.06 & 2.06 & 2.50 \\
Mean_2 & 32.54 & 32.20 & 58.82 & 61.04 & 62.68 & 59.79 & 58.25 & 48.61 & 52.17 & 52.63 & 56.83 & 52.96 \\
SD_2 & 1.72 & 1.71 & 2.10 & 2.93 & 0.24 & 2.95 & 4.8 & 2.60 & 1.22 & 3.56 & 6.57 & 3.61 \\
Mean relative & 0.46 & 1.38 & 0.03 & 1.84 & 2.70 & 0.02 & 2.87 & 0.08 & 0.95 & 3.56 & 0.37 & 5.11 \\
error (\%) & & & & & & &
\end{tabular}

Note: Mean_1 is the mean value of soil porosity using IM; SD_1 is the standard deviation of soil porosity using IM; Mean_2 is the mean value of soil porosity using images analysis method; SD_2 is the standard deviation of soil porosity using images analysis method.

Porosities of capillary pores for each soil, measured using IM and the presented method, are listed in Table 3. Frequency analysis shows that $80 \%$ of latosolic red soils and $90 \%$ of sandy soils have relative errors $<10 \%$, while $92 \%$ of the fluvo-aquic samples have relative errors $<15 \%$. The paired samples $\mathrm{T}$ test shows that none of the results are significant for any types of soil between the two methods at $\mathrm{P}<0.01$ except for fluvo-aquic soil, which has a bulk density of $1.6 \mathrm{~g} / \mathrm{cm}^{3}$. The mean relative errors for all the soils are $<4.0 \%$ except for fluvo-aquic soil, which has a bulk density of $1.6 \mathrm{~g} / \mathrm{cm}^{3}$ (Table 3).

Table 3 Capillary porosity (\%) data obtained using two methods

\begin{tabular}{lcccccccc}
\hline & \multicolumn{3}{c}{ Sandy soil } & Latosolic red soil & \multicolumn{5}{c}{ fluvo-aquic soil } \\
\hline Density $\left(\mathrm{g} / \mathrm{m}^{3}\right)$ & 1.7 & 1.8 & 1.35 & 1.2 & 1.3 & 1.4 & 1.5 & 1.6 \\
Mean_1 & 19.35 & 20.08 & 50.19 & 31.41 & 33.08 & 37.18 & 39.03 & $41.39^{\mathrm{a}}$ \\
SD_1 & 0.76 & 0.71 & 1.08 & 2.22 & 1.66 & 1.81 & 2.26 & 0.85 \\
Mean_2 & 19.33 & 20.06 & 50.15 & 31.02 & 32.83 & 37.15 & 37.60 & $37.00^{\mathrm{b}}$ \\
SD_2 & 0.89 & 1.21 & 3.50 & 6.50 & 4.37 & 3.25 & 3.40 & 0.81 \\
Mean relative error $(\%)$ & 0.10 & 0.10 & 0.08 & 1.24 & 0.76 & 0.08 & 3.66 & 10.60 \\
\hline
\end{tabular}

Note: Mean_1 is the mean value of capillaries porosity using IM; SD_1 is the standard deviation of capillaries porosity using IM; Mean_2 is the mean value of capillaries porosity using images analysis method; SD_2 is the standard deviation of capillaries porosity using images analysis method; Different lowercase in same line means significant at $\mathrm{P}<0.01$. 
Analysis also shows that the largest capillary pore sizes for the sandy soil, latosolic red soil and fluvo-aquic soil are $0.67,0.71$, and $0.74 \mathrm{~mm}$, respectively. These results are consistent with their physical properties. The above results prove that the presented method is acceptable and can provide results with a good level of accuracy.

\section{CONCLUSIONS AND DISCUSSION}

In this paper, a digital image method was developed for the analysis of soil pores. The traditional soil physics method (IM) is used to determine the total porosity and capillary porosity, and both porosities are used to obtain image thresholds for pores and capillary pores in image analysis of thin sections of calibration samples. The total porosity and capillary porosity, as well as percentages of pores of any size, can then be determined for further soil samples. The maximum size of capillary pores in soils can also be determined. The small variation of the results proved that this method has acceptable accuracy.

Because the thresholds for the total porosity and capillary porosity are determined based on physical soil characteristics in this new method, the error associated with existing methods (caused by subjective threshold estimates) was overcome. In addition, the personal flatbed scanner is very popular, inexpensive and convenient to use with a personal computer, but also has high resolution. The commercial RS software (ENVI, PCI, ERDAS et al.) and GIS software (ArcGIS, ArcView, SuperMap et al.) are also popular and sufficient for digital image analysis of soil thin sections.

Therefore, the method presented in this paper would be convenient for use in the analysis of soil pores. It is necessary to point out that identical experimental conditions, such as the ratio of resin and dye, the scanning mode, etc., must be used for the same soil type when one uses this method, because the image thresholds are sensitive to color.

\section{ACKNOWLEDGEMENTS}

This study is part of the work of the Knowledge Innovation Project (KSCX2-YW-N-003) and the CAS Action Plan for Western China Development (KZCX2-XB2-13), and the Project for 100 Outstanding Young Scientists (Yaohu Kang) supported by the Chinese Academy of Sciences, and the Key Technologies R\&D Programs (06YFGZNC00100 and 06YFGZNC06700) supported by Tianjin Municipal Science and Technology Commission. 


\section{REFERENCES}

Adderley, W.P., Simpson, I.A., and Davidson, D.A. Colour description and quantification in mosaic images of soil thin sections. Geoderma. 2002. 108:181-- 195

Bouma, J., Jongerius, A., Boersma, O., Jager, A., and Schoonderbeek, D. The function of different types of macropores during saturated flow through four swelling soil horizons. Soil Sci. Soc. Am. J. 1977.41:945--950.

Brandsma, R.T., Fullen, M.A., Hocking, T.J., and Allen, J.R. An X-ray scanning technique to determine soil macroporosity by chemical mapping. Soil Tillage Res. 1999.50:95--98.

Chen, Y., Tarchitzky, J., Brouwer, J., Morin, J., and Banin, A. Scanning electron microscope observations on soil crusts and their formation. Soil Sci. 1980.130(1): 49--55

Cousin, I., Issa, O.M., and Bissonnains. Microgeometrical characterisation and percolation threshold evolution of a soil crust under rainfall. Catena. 2005.62:173--188.

Fox, D.M., Bryan, R.B., and Fox, C.A. Changes in pore characteristics with depth for structural crusts. Geoderma. 2004.120:109--120

Hillel, D. Fundamentals of Soil Physics. London: Academic Press. 1980.385pp.

Lawrence, G. P. Measurement of pore sizes in fine-textured soils: A review of existing techniques. J. Soil Sci. 1977.28:527--540.

Li, D.C., Velde, B., and Zhang, T.L. Observations of pores and aggregates during aggregation in some clay-rich agricultural soils as seen in 2D image analysis. Geoderma. 2004.118:191$-207$

Li, D.C., Velde, B., Delerue, F., and Zhang, T.L. Influences of experimental factors on analysis of pore structure using images of soil sections. Act Pedol. Sin. 2002.39(1):52--57

Murphy, C.P., Bullock, P., and Turner, R.H. The measurement and characterization of voids in soil thin sections by image analysis. Part I. Principles and techniques. J. Soil Sci. 1977.28:498--508.

Pagliai, M., Lamarch, M., and Lucamante, G. Micromorphometric and micromorphonlogical investigations of clay loam soil in viticulture under zero and conventional tillage. J. Soil Sci. 1983.34: 391--403.

Protz, R., and VandenBygaart, A.J.. Towards systematic image analysis in the study of soil micromorphology. Sci. Soils. 1998. 3:34--44

Singh, P., Kanwar, R.S., and Thompson, M.L. Macropore characterization for two tillage systems using resin-impregnation technique. Soil Sci. Soc. Am. J. 1991.55: 1674--1679.

Velde, B., Moreau, E., and Terribile, F. Pore network in an Italian vertisol: quantitative characterization by two dimensional image analysis. Geoderma. 1996.72:271--285.

Vogel, H.J., Kretzschmar, A. Topological characterization of pore space in soil-sample preparation and digital image-processing. Geoderma. 1996.73: 23--38

White, R.E. Principles and Practice of Soil Science: The Soil as a Natural Resource. 4th ed. UK: Blackwell Publishing. 2006.363pp. 